\title{
The Rest Test: Preliminary Findings from a Large-Scale International Survey on Rest
}

\section{Claudia Hammond and Gemma Lewis}

\begin{abstract}
In this chapter, Claudia Hammond and Gemma Lewis discuss The Rest Test, the world's largest survey into people's subjective experiences of rest, devised by an interdisciplinary team at Hubbub. The Rest Test was launched in collaboration with the BBC on Radio 4's All in the Mind, presented by Claudia, who played a key role in the survey development. Gemma led the analysis of The Rest Test results.
\end{abstract}

Keywords BBC . Interdisciplinary - Radio - Rest Test - Subjective experience $\cdot$ Psychological scales

It is common to hear the complaint that in the modern world, rest is hard to find. There are too many demands on us and not enough hours in the day. Current technology leaves us permanently on call, unable to switch

C. Hammond $(\bowtie)$

BBC Radio Science Unit, London, United Kingdom

G. Lewis

University College London, London, United Kingdom

e-mail: gemma.lewis@ucl.ac.uk

(C) The Author(s) 2016

F. Callard et al. (eds.), The Restless Compendium, DOI 10.1007/978-3-319-45264-7_8 
off. As we'll see later in the chapter, these perceptions might not have an entirely accurate basis in reality. Nonetheless, this is how many of us across the world feel about life today - as reflected in media headlines such as 'Stressed, tired, rushed: a portrait of the modern family'. ${ }^{1}$

We may complain about the incessant demands of technology such as the internet, but that same technology also provided people around the world with the opportunity to tell us what rest means to them, and gave us, as researchers, the opportunity to investigate a topic that remains empirically under-investigated. Early on in Hubbub's exploration of the topic of rest, it became clear that rest is harder to define than might be expected. A review published in 2016 emphasized that although rest is often prescribed by medical staff, the concept 'remains subjective, and is vaguely defined and often confused with sleep, limiting its utility for research and practice'. ${ }^{2}$ But if rest is different from sleep - in that it includes conscious states - what exactly does it mean to different people? Does it refer to a rested mind or a rested body? For $^{\mathrm{i}}$ some, the mind can't rest until the body is fully rested. For others it is the opposite: tiring out the body through vigorous exercise allows the mind to rest.

To investigate how people understand rest, Hubbub developed an online survey we named The Rest Test. In collaboration with the programmes that one of us (Claudia) presents on BBC Radio 4 and BBC World Service - All in the Mind and Health Check - we set out to recruit participants. Through appearances on TV and radio, as well as coverage in newspapers, social media and online (including a feature on whether or not people should worry about their wandering minds ${ }^{3}$ ), Hubbub reached out across the world. BBC World Service asked people to tweet pictures of how they like to rest in whichever country they live in, and listeners emailed the programmes - some writing, for example, about how difficult it is ever to feel at rest living amidst civil war.

The survey was long and required thought to complete, meaning that people had to give up 30-40 minutes of their time to fill it in. It was pointed out to us on Twitter that filling in a long survey wasn't the most restful of pursuits. However, that didn't stop people: more than 18,000 people from 134 countries attempted the survey, making this the world's largest ever survey on rest. On searching the literature, we found that previous studies investigating the concept of rest have been much smaller

\footnotetext{
i See also Chap. 9.
} 
(with sample sizes ranging from 10 to 1208). They have also commonly consisted of quite selective samples, such as inpatients or nurses. ${ }^{4}$ As the first large survey on rest administered to the general population, The Rest Test has included a broad cross section of people - anyone over 18 years old was welcome to participate.

One of our starting points was that different kinds of expertise would be necessary to design the survey. That way, we could try to ensure that our questions were broad enough to capture psychological, sociological and economic aspects of rest. During the development of the survey, Hubbub collaborators from a dozen different disciplines were consulted. After much discussion about surveys - their purpose, underpinning assumptions, and limitations - historians, social activists and sociologists began to contribute questionnaire items. Then a group of psychologists worked on the detailed construction of The Rest Test, with numerous opportunities for those from other disciplines to fine-tune questions and suggest alternatives. The resulting survey takes a somewhat unusual form. As well as the inclusion of well-validated, published scales such as the Hexaco- $60^{5}$ and the Flourishing Scale, ${ }^{6}$ we included both specially devised questions where people could select options from long lists, and open questions to allow people to respond freely in their own words.

People completed the two-part survey online, with the option to return to the survey during the next seven days if they didn't have time to finish it. The first part covered socio-demographic data and perceptions of rest. For example, we have data on country of residence, income, gender, whether the person cared for another, levels of physical activity, benefits and disability. We also have some level of detail on people's working patterns to allow us to investigate how zero-hour contracts (which allow employers to hire staff with no guarantee of work), split shifts, worklessness and commuting times affect people's feelings about rest. If you have little choice about when to take rest, do you associate it with relaxation?ii

\section{What Is Rest and How Do People like to Do It?}

When we gave people a list of words and asked which word best described what rest meant to them, the most commonly cited word was relaxing, followed by peaceful/calming, comfortable, recuperative and sleep. A

\footnotetext{
ii See Chap. 21.
} 
small proportion of people chose the words rare, stress-inducing, anxietyinducing and guilt-inducing. Significantly more women than men did this. But we also gave people a free text box where they could explain in their own words what rest means to them. Table 8.1 gives a small selection of these words.

It is notable that some people selected words suggesting a more conflicted relationship with rest. The words in the right hand column indicate that rest can be hard to find or difficult to experience without feelings of guilt. Words such as 'worrying', 'challenging' and 'annoying' suggest that, for some, the negative associations with rest go even further.

We also asked people to select from a list of 25 activities those that they found most restful. Table 8.2 shows the top 20 activities. Many of the most popular activities suggest escapism, either from other people or

Table 8.1 Responses to The Rest Test question: In your own words, what does rest mean to you?

\begin{tabular}{lllll}
\hline Enjoyable & Breathing space & Fields & Undisturbed & Aches \\
Dissociated & Clarifying & Animals & Quiet & Not permissible \\
Respite & Necessary & Privacy & Cooperation & Elusive \\
Positive & Rumination & Switching off & Peaceful & Fragile \\
Free & Humour & Creative & Concentration & Overlooked \\
Warm & Daydream & Inventive & Being dozy & $\begin{array}{c}\text { Difficult to } \\
\text { reach }\end{array}$ \\
& & & & Challenging \\
Personal & Reading & Distracting & Daydreaming & Annoying \\
Free & Socializing & Thoughtful & Motionless & Anging \\
Space & Effortlessly & Uplifting & No velocity & Worrying \\
Restorative & Happy & Rebalancing & Bliss & Indulgent \\
Fulfilling & Mindless & Laughter & Joy & Guilty secret \\
Quiet & Unthinking & Important & Pleasurable & Frowned \\
& & & & upon by \\
Dreamy & Disconnected & Deliberate & Other worldly & Others \\
Healthy & Balance & Contemplative & Blank & Fidget \\
Disengagement & Energetic & Reflective & Beautiful & Selfish \\
Still & Not tense & Hygge & Regenerative & Guilty \\
Healing & Enriching & Safe & Me time & Unjustified \\
Delicious & Sunny & Warm bath & Precious & Dark \\
Distracting & Sublime & Strived for & Yearned for & Waste of time \\
Unwind & Cool, dark & Void & Warmth & Idleness \\
Gift & Gentle smile & Serene & Recumbent & Feeble \\
Inspiring & Liberty & Recuperative & Choice & Irritating \\
& & & &
\end{tabular}

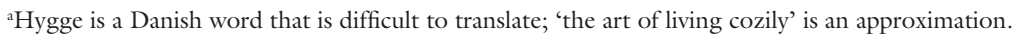


Table 8.2 Activities considered by The Rest Test respondents to be restful, in order of the most to least popular

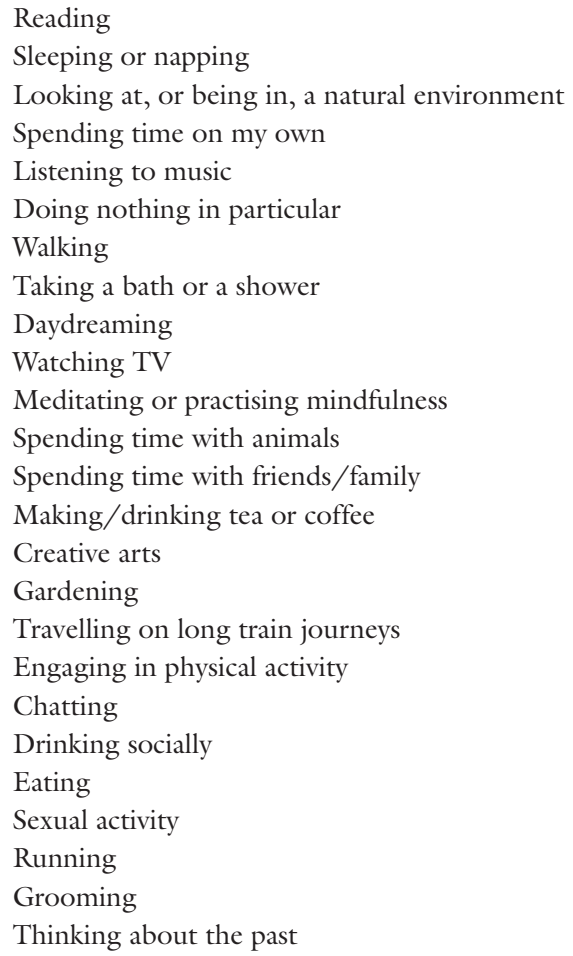

from the built environment. iii 'Spending time on my own' and 'being in, or looking at, a natural environment' were both ranked highly. Spending time with friends and family, and chatting and socializing came further down. When we say we need more rest, is it more that we yearn for time away from other people?

More women than men selected reading as restful, while more men selected listening to music. Notice that physical activity comes higher than chatting or drinking socially. A repeated theme in our research is that a

iii Cf. Chap. 12. 
substantial minority considers physical exercise not to be the opposite of rest, but to be restful in itself.

The second part of the survey included several well-validated scales frequently used in psychological research. We examined well-being using The Flourishing Scale, Satisfaction with Life Scale and The Scale of Positive and Negative Experience. On this latter scale, people who said they had more rest in the last 24 hours scored more highly on subjective well-being, while people who considered themselves in need of more rest and who believe they get less rest than others scored less highly. This might suggest that rest leads to higher well-being, but we must remember that this survey takes a snapshot in time and so we can't tell which came first - the amount of rest a person believes they get or their well-being. It is possible that people who were feeling unhappy while they filled in the survey might have underestimated the amount of rest they had.

\section{How Does the Modern World of Work} Affect Our Ability to Rest?

If someone asks how things are going, many of us tend to answer, 'Oh fine, very busy. Bit too busy'. This feels true, but of course there's also an element of status in this claim. If you say you are busy, then it implies you are wanted. You are in demand. As the time-use researcher Jonathan Gershuny puts it, busyness has become 'a badge of honour'. ${ }^{7}$ In contrast to the nineteenth century, in many parts of the world today it is work and not leisure that gives us social status. ${ }^{\text {iv }}$

We say we need more time to relax and that new technology means we are forever on call. But these complaints are nothing new. With each technological invention - such as the locomotive, the telephone and the telegram - people have expressed the fear that it placed more burdens upon us and made life feel more pressured. ${ }^{8}$

It is also common for people to overestimate the total number of hours they work. For this reason, many time-use surveys ask people to think back to the previous day or week, rather to think of a typical day or week. ${ }^{9}$ In The Rest Test, we asked people not how much they rest in a typical day, but how many hours of rest they had in the past 24 hours. Of course, it is possible that, for some, the previous day was unusually restful or unrestful,

${ }^{\text {iv }}$ Cf. Chap. 22. 
but in a large study these fluctuations should even out. When asked how much rest respondents had had in the past 24 hours, responses ranged from 0 to 14 hours, averaging at approximately 3 hours. Thirty two per cent of the people who completed the survey think they need more rest than the average person. From The Rest Test it is clear that many of us feel harried: 68 per cent would like more time to rest.

Research on time use in Europe and the United States shows that although most of us say we feel busier, average working hours have not increased in the past half century and in fact we have more spare time for resting than we used to. ${ }^{10}$ So why doesn't it feel like that? There are several possible explanations. Time use surveys and The Rest Test provide us with averages, and so there are of course some people who have very little spare time to rest and others, who might be jobless or unwell, for example, who might have more time to rest, but who experience this as an enforced rest. Perhaps we have time to rest, but don't feel fully able to switch off, as some of those more negative words regarding rest suggest. Digital technology is often blamed here, but so far there is a lack of good evidence to suggest that screens are as bad as is sometimes claimed. Much of the time they are used to stay connected with others.

There is also another possibility, identified by the sociologist Judy Wajcman. ${ }^{11}$ She has observed that the problem is not so much the total number of hours worked, as the irregularity of those hours. Fewer people work 9-5 than previously. How many of us could arrange on the spur of the moment to meet ten friends at 5.30 the same afternoon? Probably not very many of us, because some friends will be working, others will be picking up children or will already have other commitments. The findings of The Rest Test bear this out to some extent. People working shifts, especially shifts that include nights, considered themselves to be less rested.

The fact that thousands of people were prepared to spend time online telling us what they thought about rest demonstrates the broad spectrum of public interest in this topic. Of course, this was a self-selecting sample (and largely from the UK, the rest of Europe or North America). Perhaps the people who chose to complete the survey felt particularly strongly about the need for rest. The size of the response might also suggest that despite what we say, we like using digital technology to engage in this way. Many people, it seems, would like to have more time to rest and to have more time away from other people. Perhaps it's not the total hours resting or working that we need to consider, but the rhythms of our work, rest, and time with and without others. 
Acknowledgements The development of The Rest Test was a collaborative endeavour; contributors included Ben Alderson-Day, Josh Berson, Felicity Callard, Charles Fernyhough, Des Fitzgerald, Louise Gregor, Daniel Margulies, Giulia Poerio, Jonathan Smallwood and Tal Yarkoni.

The Rest Test was granted ethical approval by the Ethics Advisory Subcommittee, Department of Psychology, Durham University. All data from The Rest Test, together with explanations of how we analysed the data, is, at the time of writing, in preparation for submission to a peer-reviewed journal.

\section{NoTES}

1. Claire Cain Miller, 'Stressed, Tired, Rushed: A Portrait of the Modern Family' The New York Times (November 4, 2015), accessed June 22, 2016, http://www.nytimes.com/2015/11/05/upshot/stressed-tired-rushed-aportrait-of-the-modern-family.html?_r=1.

2. Esther I. Bernhofer, 'Investigating the Concept of Rest for Research and Practice', Journal of Advanced Nursing 72, no. 5 (2016): 1012-22.

3. Claudia Hammond, 'Why We Should Stop Worrying about Our Wandering Minds', BBC Future (6 November 2015), accessed June 22, 2016, http:// www.bbc.com/future/story/20151106-why-we-should-stop-worryingabout-our-wandering-minds.

4. See also the studies reviewed in Bernhofer, 'Investigating the Concept of Rest for Research and Practice'.

5. Michael C. Ashton, and Kibeom Lee, 'The HEXACO-60: A Short Measure of The Major Dimensions of Personality'. Journal of Personality Assessment 91, no. 4 (2009): 340-45.

6. Ed Diener et al., 'New Well-Being Measures: Short Scales to Assess Flourishing and Positive and Negative Feelings', Social Indicators Research 97, no. 2 (2009): 143-56.

7. Jonathan Gershuny, 'Busyness as the Badge of Honour for the New Superordinate Working Class. ISER Working Papers Number 2005-9' (Colchester: Institute for Social and Economic Research, University of Essex, n.d.).

8. Mark Jackson, The Age of Stress: Science and the Search for Stability (Oxford: Oxford University Press, 2013).

9. Liana C. Sayer, 'Trends in Women's and Men's Time Use, 1965-2012: Back to the Future? Pennsylvania State University National Symposium on Family Issues (NSFI) Book Series', in Gender and Couple Relationships, ed. Susan M. McHale et al. (Cham: Springer, 2016). 
10. Mark Aguiar and Erik Hurst, 'Measuring Trends in Leisure: The Allocation of Time Over Five Decades', Quarterly Journal of Economics 122, no. 3 (2007): 969-1006.

11. Judy Wajcman, Pressed for Time: The Acceleration of Life in Digital Capitalism (Chicago, Ill.: Chicago University Press, 2015).

\section{FurThER READING}

Hammond, Claudia. Time Warped: Unlocking the Mysteries of Time Perception. Edinburgh: Canongate, 2012.

Claudia Hammond is a broadcaster, writer and psychology lecturer. She is the presenter of All in the Mind and Mind Changers on BBC Radio 4, and Health Check on BBC World Service Radio and BBC World News TV. She is an Associate Director of Hubbub.

Gemma Lewis is an academic in the Division of Psychiatry at University College London. Her research currently focuses on the causes, prevention and treatment of depression using epidemiological methods and statistics.

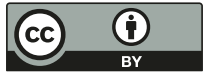

This chapter is distributed under the terms of the Creative Commons Attribution 4.0 International License (http://creativecommons.org/ licenses/by/4.0/), which permits use, duplication, adaptation, distribution and reproduction in any medium or format, as long as you give appropriate credit to the original author(s) and the source, a link is provided to the Creative Commons license and any changes made are indicated.

The images or other third party material in this chapter are included in the work's Creative Commons license, unless indicated otherwise in the credit line; if such material is not included in the work's Creative Commons license and the respective action is not permitted by statutory regulation, users will need to obtain permission from the license holder to duplicate, adapt or reproduce the material. 